\title{
Correspondence
}

\section{Coronary artery disease is associated with Alzheimer disease neuropathology in APOE4 carriers}

To the Editor: Beeri et al. describe an interesting postmortem study of Alzheimer disease (AD) patients and controls. ${ }^{1}$ We have also investigated coronary atherosclerosis, cardiovascular disease, and cardiac valve pathology in $\mathrm{AD}$ subjects and controls. ${ }^{2}$

The number of autopsies examined in our study was similar to that reported by Beeri et al. We analyzed general systemic autopsy data from 84 neuropathologically confirmed AD patients and from 60 non-AD control patients using a grade of membership model. All cases of AD were Braak stage IV, V, or VI. Consistent with reports from our center ${ }^{3}$ and others, the late onset $\mathrm{AD}$ groups had elevated APOE e4 frequency. However, the late onset AD groups also had frequent mitral and aortic valve dilation, evidence of ventricular pathology, or both.

In contrast to the report by Beeri et al., we observed only modest systemic and coronary atherosclerosis in the late onset $\mathrm{AD}$ cases. Systemic or coronary atherosclerosis was more common in the control groups and was associated with younger age at death. ${ }^{2}$ The finding of mitral and aortic valve damage, and evidence of ischemic injury to the left ventricular myocardium for the $\mathrm{AD}$ groups, are consistent with the hypothesis that myocardial pathology may contribute to brain hypoperfusion, which may in turn contribute to dementia and possibly to $\mathrm{AD}$ pathogenesis.

We have also reported loss of cerebrovascular smooth muscle actin in subjects with $\mathrm{AD} .^{4}$ This pathologic change is amplified in subjects with APOE e4. ${ }^{4}$ It is possible that physiologic factors associated with loss or deficient function of smooth muscle actin contributes directly to aortic and mitral valve injury and impaired myocardial contractility. Suboptimal myocardial contractility due to loss of smooth muscle actin or coronary atherosclerosis which causes impaired perfusion of the myocardium may have a negative impact on cardiac output which may also reduce healthy cognitive function. Thus, a constellation of related pathophysiologic events may come together to cause $\mathrm{AD}$ pathology and dementia. Further research is needed to address these issues in a prospective longitudinal study with complete and detailed neuropathology and systemic autopsy analysis.

Christine M. Hulette, Kathleen Welsh-Bohmer, Durham, NC

Disclosure: The authors report no conflicts of interest.

Reply from the Authors: Drs. Hulette and Welsh-Bohmer cite a study by Corder et al. ${ }^{2}$ published after our study ${ }^{1}$ was accepted for publication. Corder et al. showed more coronary artery atherosclerosis in a control group than in severe late-onset $\mathrm{AD}$. At face value, this apparently contradicts our findings of positive associations between coronary artery atherosclerosis and AD neuropathology. However, this discrepancy may represent differences in methodology and group assignment of study subjects.

In our study, we used the full spectrum of $\mathrm{AD}$ neuropathology (from none to severe) and corrected for confounding variables such as age at death and body mass index (BMI). Not controlling for these variables reduced the observed associations between coronary artery atherosclerosis and $\mathrm{AD}$ neuropathology.

Corder et al. used grade of membership analysis to define five prototypical subgroups. Three groups had clinically diagnosed dementia (I, early onset; IV, late onset males; and V, late onset females) and two (II, mostly cancer; and III, no cancer) did not. The clinically demented groups had neuropathologically confirmed late stage $\mathrm{AD}$. However, $43 \%$ of group III had neuropathologic possible $\mathrm{AD}$. The control groups were substantially younger and had higher $\mathrm{BMI}$ than the $\mathrm{AD}$ groups, but these group differences were not factored into the statistical analyses. The apparent differences between study results may be attributed to the effects of age, BMI, and the inclusion of cases with enough neuropathology to warrant a diagnosis of possible $\mathrm{AD}$ in the control groups in Corder et al.'s study. ${ }^{2}$

The Ervin et al. ${ }^{4}$ results that report loss of cerebrovascular smooth muscle actin in subjects with $\mathrm{AD}$ complement our findings. These results, together with Corder's finding of mitral and aortic valve damage in $\mathrm{AD}$ subjects, suggest that aging-related cardiovascular pathology, irrespective of the specific cardiovascular lesion, might affect the severity of AD neuropathology. These processes may occur indirectly through hypoperfusion or more directly through brain and systemic vascular pathology. ${ }^{5}$ Thus, $\mathrm{AD}$ neuropathology and dementia may be associated with systemic cardiovascular deterioration. ${ }^{6}$

If these conclusions are supported by additional studies then approaches to improve cardiovascular health in the elderly may lead to additional neuropathologic and cognitive benefits. ${ }^{7}$

M. Schnaider Beeri, M. Rapp, J.M. Silverman, J. Schmeidler, H.T. Grossman, J.T. Fallon, D.P. Purohit, D.P. Perl, A. Siddiqui, G. Lesser, C. Rosendorff, V. Haroutunian, New York, NY

Disclosure: The authors report no conflicts of interest. Supported by NIA P50 AG05128 \& R01 AG07198 and Glaxo Smith-Kline.

Copyright @ 2007 by AAN Enterprises, Inc.

\section{References}

1. Beeri MS, Rapp M, Silverman JM, et al. Coronary artery disease is associated with Alzheimer disease neuropathology in APOE4 carriers. Neurology 2006;66:1399-1404.

2. Corder EH, Lockhart E, Ervin JF, et al. Cardiovascular damage in Alzheimer disease: autopsy findings from the Bryan ADRC. J Biomed Biotechnol 2005;2:189-197.

3. Saunders IS, Strittmatter WJ, Schmechel D, et al. Association of apolipoprotein $\mathrm{E}$ allele epsilon 4 with late-onset familial and sporadic Alzheimer's disease. Neurology 1993;43:1467-1472.

4. Ervin JF, Pannell C, Szymanski M, Welsh-Bohmer K, Schmechel DE, Hulette CM. A quantitative analysis of vascular smooth muscle actin in Alzheimer's disease. J Neuropathol Exp Neurol 2004;63:735-741.

5. Kalback W, Esh C, Castano EM, et al. Atherosclerosis, vascular amyloidosis and brain hypoperfusion in the pathogenesis of sporadic Alzheimer's disease. Neurol Res 2004;26:525-539.

6. Newman AB, Fitzpatrick AL, Lopez O, et al. Dementia and Alzheimer's disease incidence in relationship to cardiovascular disease in the Cardiovascular Health Study cohort. J Am Geriatr Soc 2005;53:1101-1107.

7. Roher AE, Kokjohn TA, Beach TG. An association with great implications: vascular pathology and Alzheimer disease. Alzheimer Dis Assoc Disord 2006;20:73-75.

\section{Hematoma growth is a determinant of mortality and poor outcome after intracerebral hemorrhage}

To the Editor: I read with interest the article by Davis et al. ${ }^{1}$ in which they noted hematoma growth within 24 hours as the most common determinant of subsequent mortality and morbidity in 218 prospectively followed patients. A surprisingly high proportion of patients $(72 \%)$ demonstrated measurable hematoma enlargement. The following case illustrates that the growth of perihematoma edema rather than the enlarging hemorrhage may also be causative.

A 42-year-old chronically hypertensive woman was awakened in the middle of night with severe headache followed by stupor. She was intubated in the emergency room. Initial examination revealed eye opening with mild left gaze preference and left limb withdrawal only from a painful stimulus. Pupils were midsize and reactive. Emergent CT scan, 3 hours after the symptom onset, showed a left striatocapsular hemorrhage with a rim of edema (figure, A). Hemorrhage measured $4.8 \times 2.9 \mathrm{~cm}$. Six millimeters of maximal midline shift was noted. Mannitol infusion was started. Next day both pupils became unreactive at $2.5 \mathrm{~mm}$ with otherwise intact brainstem reflexes. Repeat CT scan, now 30 hours after the ictus, showed the hemorrhage did not enlarge but the perilesional edema was more conspicuous (figure, B). Midline shift worsened to $10 \mathrm{~mm}$. Ventriculostomy was inserted with normal intracranial pressure reading of $8 \mathrm{~mm} \mathrm{Hg}$ (normal $<15 \mathrm{~mm} \mathrm{Hg}$ ). On the fourth hospital day, both pupils remained unreactive but now asymmetric with left at $4 \mathrm{~mm}$, and right at $2 \mathrm{~mm}$. 
Follow-up CT now showed worsening of midline shift to $15 \mathrm{~mm}$ without expansion of hemorrhage (figure, C). On the 10th hospital day, pupils were equal in size and sluggishly reactive. On the 12 th day, following successful extubation a day earlier, she died.

Along with hemorrhage expansion, perihematoma edema enlargement may also result in subsequent clinical deterioration in many patients with intracerebral hemorrhage (ICH). ${ }^{2}$ Severity of midline shift mirrored clinical change in this case, but as Papo et al. ${ }^{3}$ noted, intracranial pressure measurement may not correlate. This case reflects difficulties in treatment strategy whether in expanding hemorrhage or perilesional edema.

Gregory Y. Chang, Orange, $C A$

Disclosure: The author reports no conflicts of interest.

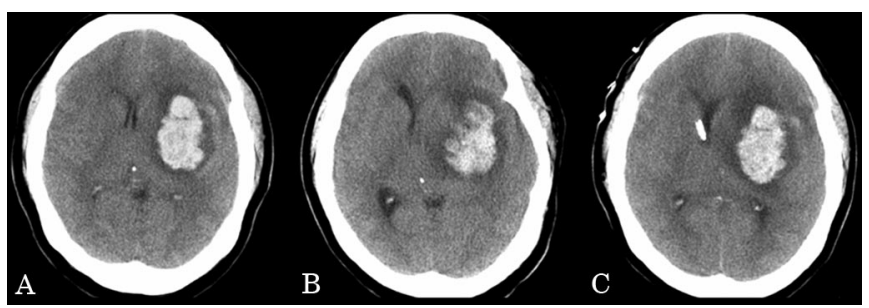

Figure. (A) Three hours after the ictus; (B) at 30 hours, perihematoma edema has increased; (C) fourth day, marked shift due to edema without hematoma enlargement.

Reply from the Authors: We thank Dr. Chang for his letter. The aim of our article was to demonstrate that hematoma expansion is a significant, independent predictor of adverse outcomes after $\mathrm{ICH}$, over and above established baseline prognostic indicators. ${ }^{1}$ We agree that, in addition to hematoma expansion, the development of edema is an important cause of subsequent clinical deterioration following ICH. These pathophysiologic sequelae are likely to be closely related.

Using CT, there is a correlation between hematoma volume and the extent of absolute perilesional edema, although no correlation between baseline relative edema volume and subsequent hematoma growth was shown in one study. ${ }^{4}$ Using more sensitive MRI measures, Butcher et al. showed in a multivariate analysis that the volume of edema on MRI was highly correlated with the volume of hematoma on CT. Other determinants of edema included the time to MRI and increased perihematomal rADC values. ${ }^{5}$ This study indicated that perilesional edema is associated with enhanced diffusion of water rather than ischemia, and hence vasogenic in origin. ${ }^{5}$

Reinforcing this close association, we reported that recombinant activated factor VII (rFVIIa) reduced not only hematoma growth at 24 hours (the primary endpoint of our proof of concept study), but also the total lesion volume at 72 hours, including the volume of ICH, intraventricular hemorrhage, and edema. ${ }^{6}$ There was also a dose-response relationship. A more detailed analysis of the effects of rFVIIa on perihematomal edema will be reported by the investigators.

S.M. Davis, J. Broderick, M. Hennerici, N.C. Brun, M.N. Diringer, S.A. Mayer, K. Begtrup, T. Steiner, Victoria, Australia

Disclosure: The authors report no conflicts of interest.

Copyright $@ 2007$ by AAN Enterprises, Inc.

\section{References}

1. Davis SM, Broderick J, Hennerici M, et al. Hematoma growth is a determinant of mortality and poor outcome after intracerebral hemorrhage. Neurology 2005;66:1175-1181.

2. Mayer SA, Sacco RL, Shi T, Mohr JP. Neurologic deterioration in noncomatose patients with supratentorial intracerebral hemorrhage. Neurology 1994;44:1379-1384

3. Papo I, Janny P, Caruselli G, Colnet G, Luomgo A. Intracranial pressure time course in primary intracranial hemorrhage. Neurosurgery 1979;4: $504-511$

4. Gebel JM Jr, Jauch EC, Brott TG, et al. Natural history of perihematomal edema in patients with hyperacute spontaneous intracerebral hemorrhage. Stroke 2002;33:2631-2635.

5. Butcher KS, Baird TA, MacGregor L, Desmond PM, Tress BM, Davis SM. Peri-hematomal edema in primary intracerebral hemorrhage is plasma derived. Stroke 2004;35:1879-1885.

6. Mayer SA, Brun NC, Begtrup K, et al, for the Recombinant Activated Factor VII Intracerebral Hemorrhage Trial Investigators. Recombinant activated factor VII for acute intracerebral hemorrhage. N Engl J Med 2005;352:777-785

\section{Oxcarbazepine adjunctive therapy in infants and young children with partial seizures}

To the Editor: We appreciate that authors and researchers are challenged by significant methodologic difficulties in the implementation of clinical trials involving a pediatric population. However, we do not understand misleading or problematic interpretation and presentation of the clinical trial results. In the article by PiñaGarza et al., we believe the authors failed to straightforwardly report their findings in a number of significant ways. ${ }^{1}$

An initial concern is the objectivity of a group where only one of eight authors is not significantly financially linked to Novartis.

In the abstract section, the authors state that the most frequent adverse events (less than or equal to $10 \%$ ) were somnolence and pyrexia. However, table 4 demonstrates that the single most common adverse event in either treatment group was infections and infestations. Furthermore, the high dose oxcarbazepine group showed that $39.1 \%$ of the population had infections and infestations, a 2.8-fold increase over the comparison low dose group. Additionally, the most alarming percentage adverse event, suffered by $15.6 \%$ of the high dose group, one that represented a 9.8-fold increase over the comparison low dose group, was related to respiratory, thoracic, and mediastinal disorders. Finally, the high-dose group was the only group to suffer clinically significant EKG abnormalities.

The authors' statistical analysis was compromised by a lack of comparable study groups. The high-dose group received treatment for a duration approximately four times longer than the low-dose group (9 days vs 35 days). Furthermore, the authors appeared to reduce statistical validity by altering their randomization during the course of the study using a modified intent-to-treat (ITT) population for subsequent statistical analysis of baseline and treat- ment phase and, alternatively, using unmodified ITT for statistical evaluation of efficacy. This introduces bias and thereby reduces the power of the conclusions regarding efficacy.

Finally, the stated primary objective was to evaluate the efficacy and safety of oxcarbazepine in children ages 1 month to less than 4 years with Type 1 seizures. However, the efficacy results additionally included type 2 seizure events, inflating the efficacy significance from $p=0.043$ to $p=0.020$. Separately, the authors fail to adequately detail the safety issues of this drug in their abstracted conclusions. The final paragraph of the article merely summarizes the safety and side-effects, suggesting that oxcarbazepine was generally well tolerated, a conclusion that is not consistent with their adverse event data.

Stefan P. Kruszewski, MD, Steven G. Klotz, MD, Harrisburg, PA

Disclosure: The authors report no conflicts of interest.

Reply from the Authors: Drs. Kruszewski and Klotz recognize the difficulties in conducting a clinical trial in pediatric patients, particularly one which includes a seriously ill population at risk for increased seizure activity and potential complications. ${ }^{1}$ This trial enrolled very young patients ( 1 month to $<4$ years old $)$ with inadequately controlled partial seizures already receiving up to two concomitant antiepileptic drugs. We used a unique and creative study design comparing low and high doses of oxcarbazepine and not placebo in an attempt to not endanger these patients with severe epileptic syndromes.

The adverse events as presented in table 4 are not specific in that the events are presented by primary organ class and not by individual preferred terms aside from somnolence and pyrexia 
which were the only two adverse events to occur in $>10 \%$ of the patients in either dose group. The higher incidence of adverse events reported for the high-dose vs the low-dose group is likely a reflection of the 3.5-fold longer duration of exposure to study drug of the highdose group (35 days) compared to the low-dose group (9 days). For the organ classes, infections and infestations and respiratory, thoracic, and mediastinal disorders, none of the individual adverse events occurred in more than $10 \%$ of the patients in either group.

As acknowledged in our article, the study was limited by the short duration and absence of a placebo group. Thus, a low- and high-dose group design was used in an attempt to allow meaningful comparison without placing the children at undue risk. In order to accomplish this, the high-dose group required a 26-day titration period to reach the planned dose, which the low-dose group did not need. To assess efficacy, both the baseline EEG and the EEG obtained over the last 72 hours of treatment were required. In a classic ITT population analysis, any patient missing one value would be excluded as well. The modified ITT statistical analysis employed was equivalent to a classic ITT analysis minus the patients with missing EEG values.

The efficacy results as presented reflect the planned primary assessment with type 1 seizures to demonstrate that the high-dose group is more effective than the low-dose group ( $p=0.043$ ). Type 1 and type 2 seizures were combined for only one planned secondary assessment and these data are presented separately as appropriate.

We acknowledge the stated concern that seven of the eight authors have disclosed a relationship to the trial sponsor, either as an employee or a recipient of honoraria or grant funding. The disclosure statements on the front page of Neurology articles are specifically intended to report relevant information about investigators and authors to allow objectivity on the readers' behalf and enable the scientific community to draw their own conclusions about any potential conflict of interest. The information about the authors was adequately disclosed.

J.E. Piña-Garza, Nashville, TN; R. Espinoza, MD, Cuauhtemoc, Mexico; D. Nordli, MD, Chicago, $I L$; D.A. Bennett, PhD, S.

Spirito, MS, MPH, T.E. Stites, PhD, D. Tang, PhD, East

Hanover, NJ; Y. Sturm, PhD, Basel, Switzerland

Disclosure: J.E.P.-G. serves as a consultant and speaker for Novartis Pharmaceuticals Inc. D.N. serves as a consultant for and has received honoraria in excess of $\$ 10,000$ from Novartis Pharmaceuticals Inc. D.B., S.S., T.S., and D.T. are employees of Novartis Pharmaceuticals Inc. and D.T. and D.B. are stockholders in Novartis Pharmaceuticals Inc. Y.S. is an employee and stockholder in excess of $\$ 10,000$ in Novartis Pharma AG. R.E. has no financial interests to disclose. This study was sponsored by Novartis Pharmaceuticals Inc.

Copyright $\odot 2007$ by AAN Enterprises, Inc.

\section{Reference}

1. Piña-Garza JE, Espinoza R, Nordli D, et al. Oxcarbazepine adjunctive therapy in infants and young children with partial seizures. Neurology 2005;65:1370-1375.

\section{Correction}

\section{Infusion-related hypersensitivity reactions during natalizumab treatment}

In the article "Infusion-related hypersensitivity reactions during natalizumab treatment" by J.T. Phillips et al. (Neurology 2006;67:1717-1718), there are two errors in the table. The asterisk footnote begins with the incorrect number of patients; it should read "*A total of 26 patients experienced hypersensitivity reactions...." In addition, the symbol after "Anaphylactic/ anaphylactoid reaction" should have the symbol for urticaria plus other systemic symptoms (§). The table is reprinted with corrections below:

Table Hypersensitivity reactions in the AFFIRM study

$\begin{array}{lr}\text { No. of hypersensitivity reactions } & 28^{*} \\ \text { Nonserious reactions } & 20 \\ \text { Urticaria or generalized urticaria } & 13 \\ \text { Allergic dermatitis } & 2 \\ \text { Hypersensitivity } & 5 \\ \text { Serious reactions } \dagger & 8 \\ \text { Urticaria } & 1 \neq \\ \text { Hypersensitivity } & 2 \\ \text { Anaphylactic/anaphylactoid reaction§ } & 5 \\ \quad \text { (serious systemic reactions) } & \end{array}$

* A total of 26 patients experienced hypersensitivity reactions in the AFFIRM study; 25 natalizumab patients experienced 27 hypersensitivity reactions and one placebo patient experienced urticaria. Of the natalizumab-treated patients, one patient with a reaction called hypersensitivity during the seventh infusion was redosed with natalizumab (protocol violation) and subsequently experienced an anaphylactic/anaphylactoid reaction during the 13th infusion (Case 2, this report). This patient, as well as another patient with two reactions, is counted twice in the table, so that the number of reactions in natalizumab patients adds up to 27.

$\dagger$ Hypersensitivity reactions reported by the investigators as a serious adverse event.

$\doteqdot$ Placebo patient.

$\S$ Defined as urticaria plus other systemic symptoms. 


\title{
Neurology
}

\author{
Correction \\ Neurology 2007;68;473 \\ DOI 10.1212/01.wnl.0000256835.74484.13
}

This information is current as of February 5, 2007

\section{Updated Information \&} Services

\section{Citations}

Permissions \& Licensing

Reprints including high resolution figures, can be found at: http://n.neurology.org/content/68/6/473.full

This article has been cited by 1 HighWire-hosted articles: http://n.neurology.org/content/68/6/473.full\#\#otherarticles

Information about reproducing this article in parts (figures,tables) or in its entirety can be found online at:

http://www.neurology.org/about/about_the_journal\#permissions

Information about ordering reprints can be found online:

http://n.neurology.org/subscribers/advertise

Neurology ${ }^{\circledR}$ is the official journal of the American Academy of Neurology. Published continuously since 1951, it is now a weekly with 48 issues per year. Copyright. All rights reserved. Print ISSN: 0028-3878. Online ISSN: 1526-632X.

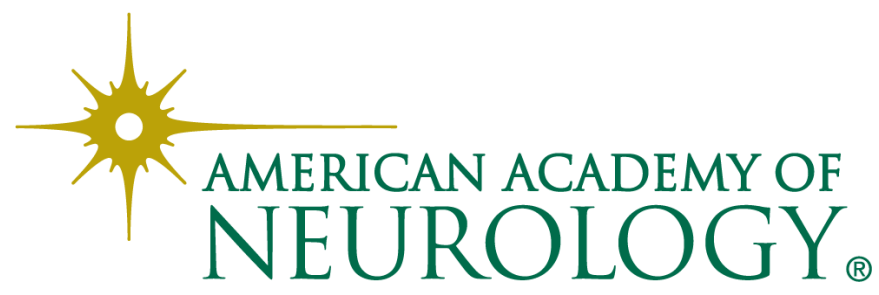

